[0212-7199 (2004) 21: 1; pp 20-22] ANALES DE MEDICINA INTERN Copyright @ 2004 ARAN EDICIONES, S.L.

An. Med. InTERnA (Madrid) Vol. 21, N. ${ }^{\circ} 1$, pp. 20-22, 2004

\title{
Infección invasiva por Aspergillus terreus tratada con éxito con anfotericina B liposomal
}

\author{
S. SUÁREZ ORTEGA, ${ }^{\text {a }}$ I. CAMPOS-HERRERO NAVAS ${ }^{1}$, M. A. LIMERES \\ GONZÁLEZ², F. DÍAZ LÓPEZ ${ }^{3}$, J. M. ZARZALEJOS ANDES, Mª E. ARKUCH \\ SAADE
}

Servicios de Medicina Interna, ${ }^{1}$ Microbiología, ${ }^{2}$ Anatomía Patológica y ${ }^{3}$ Neumología. Hospital General de Gran Canaria Dr. Negrín. Las Palmas de Gran Canaria

\begin{abstract}
INVASIVE INFECTION DUE TO ASPERGILLUS TERREUS TREATED SUCCESSFULLY WITH LIPOSOMAL ANPHOTERICIN B
\end{abstract}

\begin{abstract}
RESUMEN
Una mujer de 75 años ingresó en nuestro hospital para evaluación de debilidad en miembros inferiores y deterioro. Se detectaron múltiples fracturas vertebrales por aplastamiento, con dudosa discitis, una lesión cavitada en lóbulo superior derecho y otro infiltrado en lóbulo superior izquierdo, observándose en la PAAF de la lesión cavitada un hongo filamentoso y siendo el cultivo del broncoaspirado positivo para Aspergillus terreus. Con tratamiento prolongado con anfotericina B liposomal desapareció la lesión, permaneciendo posteriormente con itraconazol oral 3 meses. Los datos clínicos y analíticos demuestran la existencia de una colagenosis tipo síndrome Overlap, con criterios de síndrome antifosfolípido secundario. Se comenta la rareza de la infección por Aspergillus terreus en pacientes que no han ingresado en Medicina Intensiva y la buena respuesta al tratamiento con anfotericina B liposomal, que contrasta con la elevada mortalidad referida en una revisión reciente. Otros aspectos a comentar son la coexistencia con una colagenosis y un síndrome antifosfolípido secundario con los títulos más elevados de ACA IgM que hemos encontrado en la literatura.
\end{abstract}

PALABRAS CLAVE: Aspergilosis invasiva. Aspergillus terreus. Corticoides. Colagenosis. Anfotericina B liposomal.

\begin{abstract}
A woman of 75 years old was admitted at our hospital for evaluation of worsening and weakness in inferior limbs. Several vertebral fractures by crushing, one doubtful discitis, an infitrate with cavitation in the right superior lobe and one infiltrate in the left superior lobe were detected. In the biopsy of the consolidation a filamentous fungus was watched and in the bronchial washing specimen culture grew Aspergillus terreus. The infiltrates disappeared with liposomal Anphotericin B remaining with oral Itraconazol durin three months more. The clinical and analytical data demonstrate the existence of a Overlap syndrome associate to antiphospholipid-antibody syndrome. We comment the peculiarity of the infection by Aspergillus terreus in patients who have not been in critical care and the good response at treatment with liposomal Anphotericin B. It contrasts with the high mortality referred in a recent review. Other aspects to comment are the coexistence with a collagen vacular and an antiphospholipid-antibody syndrome with the higher titles of IgM ACA that we have found in literature.
\end{abstract}

KEY WORDS: Invasive aspergillosis. Aspergillus terreus. Corticoid. Collagen disease. Liposomal Anphotericin B.

Suárez, Ortega S, Campos-Herrero Navas MI, Limeres González, MA, Díaz López, F, Zarzalejos Andes JM, Arkuch Saade ME. Medicina Interna.Infección invasiva por Aspergillus terreus tratada con éxito con anfotericina B liposomal. An Med Interna (Madrid) 2004; 21 : 20-22.

\section{INTRODUCCIÓN}

La infección por Aspergillus spp. es típica de pacientes inmunodeprimidos (1-4). De las distintas especies patógenas conocidas de aspergillus para la especie humana la infección por Aspergillus terreus es poco frecuente, y, habitualmente se asocia a estancias en las unidades de medicina intensiva. En una revisión reciente publicada en la más prestigiosa revista de enfermedades infecciosas se comparan 11 casos de aspergilosis invasiva por Aspergillus terreus diagnosticados en los últimos 12 años con otros 19 casos encontrados en la literatu- ra. La mortalidad de los pacientes de la institución fue de 10 de los 11 pacientes (5). En el presente caso se trata de una mujer anciana con colagenosis tratada con esteroides que se presentó con infiltrados en ambos pulmones y una dudosa discitis vertebral y que fue diagnosticada de aspergilosis pulmonar invasiva en base a histología compatible y cultivo de Aspergillus terreus en el broncoaspirado. Con tratamiento prolongado con anfotericina B liposomal seguido de itraconazol, experimentó mejoría progresiva hasta la curación, permaneciendo asintomática al año de retirar el tratamiento antimicótico.

Trabajo aceptado: 30 de julio de 2003

Correspondencia: Saturnino Suárez Ortega. Urbanización El Arco, 16. La Atalaya. 35307 Santa Brígida, Las Palmas. Tf 928-430263. e-mail: drsuarez@hotmail.com 


\section{CASO APORTADO}

Mujer de 75 años, que es evaluada por primera vez en este hospital por trombopenia y anemia, detectándose en dicho momento por endoscopia digestiva alta Gastritis atrófica secundaria a Helicobacter pylori a la par que es diagnosticada de púrpura trombocitopénica idiopática indicándosele tratamiento erradicador y prednisona a la dosis de $2 \mathrm{mg} / \mathrm{kg} /$ día. Dos meses después de iniciar el tratamiento esteroideo sufre golpe en la zona lumbar seguido de paraparesia y dificultad para la micción y defecación. Las dos semanas previas al ingreso actual presentó secreciones respiratorias blanquecinas, tos y disfonía. Por el cuadro respiratorio y la paraparesia acude al servicio de urgencias de este hospital y se decide ingreso. Antecedentes de hipertensión arterial de larga evolución. Historia de problemas articulares secundarios a osteoartrosis difusa. Cirugía de ambas rodillas y colecistectomía. Tuvo 8 abortos, y un hijo muerto de 2.5 meses, 9 hijos viven sanos. No otros antecedentes de interés. A la exploración: consciente, orientada, colaboradora; no rigidez de cuello ni bocio. No claro distrés respiratorio, siendo la auscultación respiratoria ruda, con subcrepitantes aislados. Facies engrosada con aspecto cushingoide. No muguet. Algunas úlceras bucales. Tonos cardíacos taquiarrítmicos, algo apagados, sin soplos, con abdomen globuloso y cicatriz quirúrgica, difícil delimitar visceromegalias, portando sonda vesical y heces en pañal por incontinencia fecal. Hinchazón asimétrica de miembros inferiores con fóvea, con mayor aumento de volumen en miembro inferior derecho respecto al izquierdo. Debilidad en miembros inferiores grado $2 / 5$ de predominio proximal. No claro nivel sensitivo. De la analítica destaca: Anticuerpos antinucleares positivos patrón moteada título 1/640; anticuerpos antinucleares índice 8.56 (valores normales de 0-1.1). Anti-DNA, anti RNPSM, anti-SM, anti-SSA-RO, anti-SSB-LA: negativos. Anticuerpos anticardiolipina IgG 25.2 U/GPL y anticardiolipina IgM de $610 \mathrm{U} / \mathrm{MPL} / \mathrm{ml}$; antibeta2-glipoproteína IgG 13.8 unidades (valores normales hasta 20); antibeta 2-glipoproteína IgM: >5 (índice normal de 0 a 1) anticuerpos anticentrómetro: 1/640. Crioglogulinas negativas. Anticuerpos anticitoplasma antineutrófilos, antimúsculo liso, anticélulas parietales, antimitocondrial y anti-LKM: todos negativos. Serología reagínica y treponémica luética, VIH, virus B y C de la hepatitis negativa; proteinograma e inmunoglobulinas normales; C3: $121 \mathrm{mg} / \mathrm{dl}$ (valores normales desde 90 a 180), y C4 8.28 (de 10-40 mg/dl); T4 libre 0,7 ng/dl con TSH normal. TGP 47 U/l, GGT 67 U/l, LDH 662 U/l, colesterol total $255 \mathrm{mg} / \mathrm{dl}$. Coagulación normal con test de Coombs positivo. VSG: $83 \mathrm{~mm}$ a la primera hora; plaquetas 107.000 por mm3; resto del SMA de este hospital normal. En la Rx de tórax se aprecia: Masa cavitada en lóbulo superior derecho de aproximadamente $5 \mathrm{~cm}$ de diámetro (Fig. 1). CT tóraco-abdominal: Masa de contenido cavitado a nivel de LSD de $4,7 \mathrm{~cm}$. Y pequeño infiltrado a nivel del lóbulo superior izquierdo. Broncoscopia: Cuerdas vocales normales al igual que el resto de la exploración. A través del segmento anterior del lóbulo superior derecho se aspiran secreciones y se llega a la lesión realizándose punción transbronquial. Citología de aspirado bronquial y lavado broncoalveolar negativos para malignidad, compatible con inflamación aguda; Cultivo para Micobacterias del broncoaspirado negativo; asimismo no se detecta RNA de Mycobacterium tuberculosis complex. En el cultivo para hongos del broncoaspirado se aisló Aspergillus terreus (Fig. 2). Punción de nódulo pulmonar: Cultivo para bacterias y micobacterias negativo. Tinción para Pneumocystis carinii negativo. Anatomía patológica: negativa para malignidad, observándose un hongo filamentoso (Fig. 3). Rx de columna lumbar: Severa osteopenia con aplastamiento de L1. Pérdida de altura de más del $80 \%$ con acuñamiento anterior de $15^{\circ}$. Pérdida de altura de L4. Espondilosis generalizada. RNM de columna lumbar: Se aprecian varios aplastamientos de cuerpos vertebrales a nivel de D12, L1 y L4, con afectación discal D12-L1, que sugiere discitis. Electromiograma: Compatible con neuropatía sensitivomotora axonal. Capilaroscopia: síndrome capilaroscópico distrófico de microvascularidad dérmica con desorganización capilar, ausencias moderadas dee capilares neoformados y plexos venosos visibles.

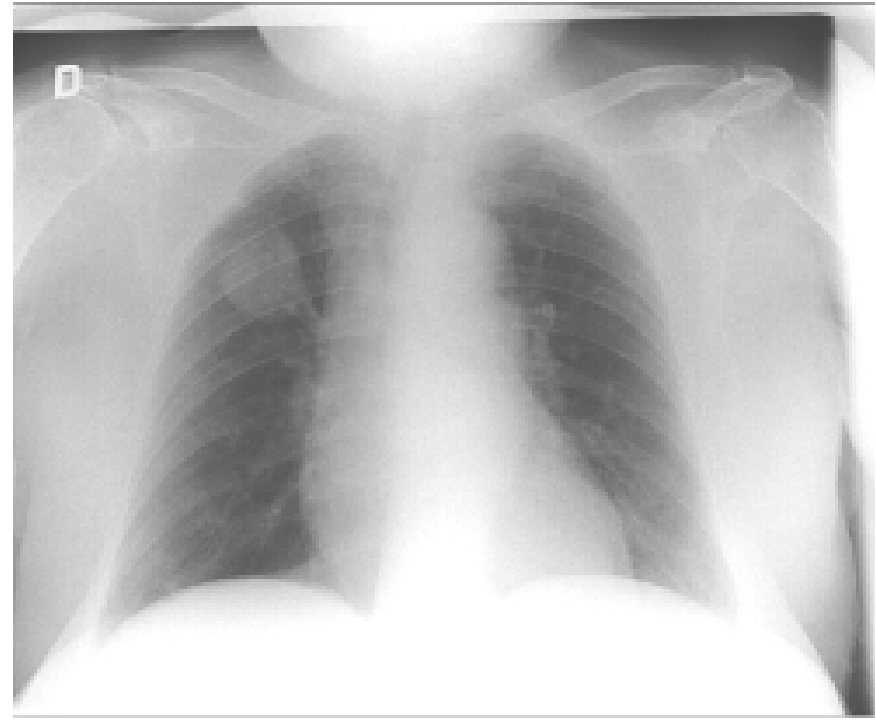

Fig. 1. Rx tórax: Se aprecia condensación LSD, con pequeña cavitación.

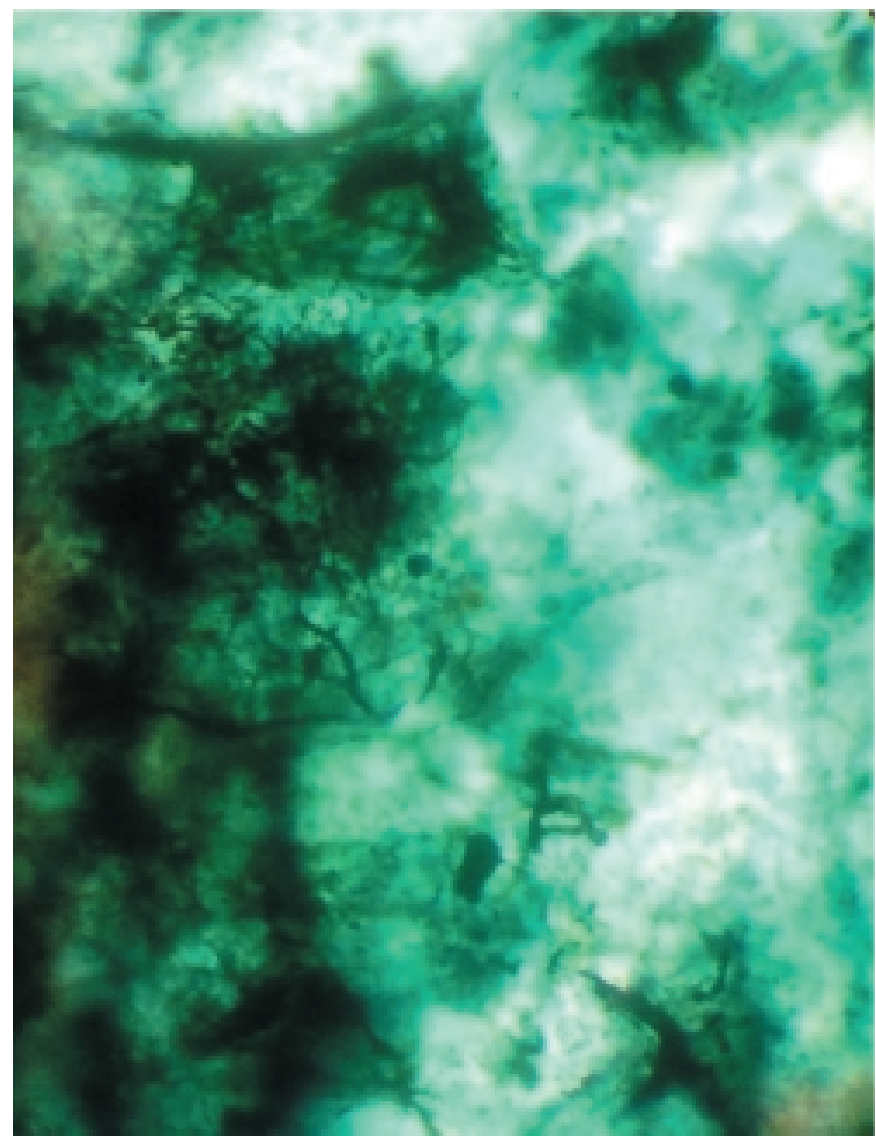

Fig. 2. Se observa colonia de Aspergillus terreus en medio de agar Czapek-dox.

No hay megacapilares. Endoscopia digestiva alta: Impacto de trozo de carne en tercio superior de esófago que se desplaza con presión hacia la cavidad gástrica. Resto normal. Electrocardiograma: arritmia completa por fibrilación auricular. Ecocardiograma: esclerosis aórtica valvular aórtica.

Desde su ingreso se evidencia semiología respiratoria activa, que se consideró posteriormente secundaria a infección invasiva por 


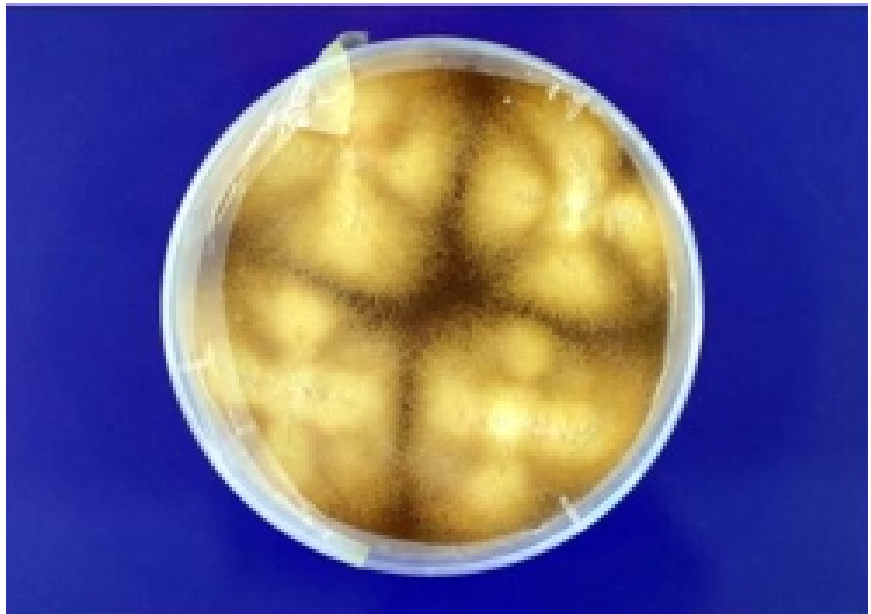

Fig. 3. Se detectan hongos filamentosos en la PAAF de la lesión pulmonar cavitada (tinción de Grocot).

Aspergillus terreus, y por lo que se indicó tratamiento con anfotericina B en la forma liposomal a una dosis de $200 \mathrm{mg} / \mathrm{iv} /$ día durante 17 días: (total: $3400 \mathrm{mg}$ ), seguido de Itraconazol a la dosis de $400 \mathrm{mg}$ al día durante 3 meses, con progresiva mejoría hasta la curación. Por el síndrome medular se indicó corsé y rehabilitación.

$\mathrm{Al}$ alta se introdujo azatioprina a la dosis de un $\mathrm{mg} / \mathrm{kg} / \mathrm{día}$, con la finalidad de reducir los esteroides, reingresando a los 5 meses con pancreatitis aguda, descartándose litiasis biliar y etilismo, asumiéndose la etiología azatioprina. En dicho ingreso se constató ademas trombosis de la bifurcacion de la vena ilíaca por lo que se indicó acenocumarol. Al año del primer ingreso aún permanecen elevados los ACA IGM a títulos de 1/160 U/MPL, los anticuerpos antinucleares y los anticentrómero, estando con dosis bajas de esteroides relativamente asintomática.

\section{DISCUSIÓN}

La existencia de un síndrome antifosfolípido de larga evolución, que en el curso evolutivo se transforma en una Colagenosis ha sido revisada recientemente (6), y corresponde claramente con este caso, en el que se constata en décadas previas la existencia de abortos de repetición. Estos múltiples abortos de repetición, seguidos de trombopenia, ACA y antibeta2-glicoproteína positivos y trombosis en la bifurcación venosa ilíaca determinan la existencia de un síndrome antifosfolípido. La colagenosis existente cumple datos de síndrome Overlap, constantándose como datos positivos manifestaciones articulares, esofágicas, engrosamiento cutáneo y trombopenia, junto a los anticuerpos ANA, anticentrómero y ACA positivos. La introducción de esteroides por la trombopenia determina un giro en la situación clínica con los aplastamientos vertebrales, el síndrome medular y la infección invasiva por Aspergillus terreus.

La infección por Aspergillus terreus es un cuadro grave que ha sido visto muy raramente en nuestro hospital, en conexión con estancias en Medicina Intensiva y, que se caracteriza por el oportunismo clásico de la infección por Aspergillus (10).

A pesar de que se ha demostrado resistencia in vitro de esta especie de Aspergillus a la Anfotericina B (7), en nuestro caso así como en otros descritos en la literatura $(5,8)$ la evolución fue buena con la terapia inicial con este antifúngico que posteriormente (17 días más tarde) se sustituyó por Itraconazol oral, manteniéndose este último hasta 3 meses. La buena evolucion con Anfotericina B liposomal en este cuadro, seguida de Itraconazol creemos que es una experiencia útil a comentar, dada la escasez de casos de esta infección que han sobrevivido con esta pauta, y la falta de una pauta idónea por definir en la infección por Aspergillus spp. $(11,12)$.

Una vez controlada la infección la paciente permanece relativamente estable, y, paradójicamente con dosis bajas de esteroides no solo no se constata sangrado sino que aparece trombosis venosa, que es lo característico del síndrome antifosfolípido, cuyo tratamiento básico es la anticoagulación (9).

En resumen, se trata de una paciente senil, con una constelación de datos clínicos y analíticos de colagenosis tipo Overlap, asociada a Síndrome antifosfolípido secundario, que tras un curso de esteroides desarrolla una infección oportunista por Aspergillus terreus, con curación a base de Anfotericina B liposomal e Itraconazol, y que un año después se encuentra relativamente asintomática, con perfil inmunológico activo.

\section{Bibliografía}

1. Denning DW. Invasive aspergillosis in inmunocompromised patients. Curr Opi Infect Dis 1994; 7: 456-462.

2. Minamoto GY, Barlam TF, Vander Els NJ. Invasive aspergillosis in patients with AIDS. Clin Infect Dis 1992; 14: 66-74.

3. Cunha BA. Infecciones relacionadas con corticosteroides en las enfermedades reumáticas. En: Picazzo JJ, Bouza E eds. Infección 2002. Servisistem 2000 SL. Bilbao 2002: 177-188.

4. Nenoff P, Horn LC, Mierzwa W, et al. Peracute disseminated fatal Aspergillus fumigatus sepsis as a complication of corticoid treated systemic lupus erythematosus. Mycoses 1995; 38: 467-471.

5. Iwen PC, Rupp ME, Langnas AN, Reed EC, Hinrichs H. Invasive pulmonary aspergillosis due to Aspergillus terreus: 12-year experience and review of the literature. Clin Infect Dis 1998; 26: 1092-1097.

6. Carbone J, Sarmiento E, Segovia P, Rodríguez-Mahou M, RodríguezMolina JJ, Fernández-Cruz E. Anticuerpos antifosfolipídicos y evolución a conectivopatía: estudio de seguimiento de mujeres con abortos recurrentes. Med Clin (Barc) 2002; 119: 681-686

7. Sutton DA, Sanche SE, Revankar SG, Fothergill AW, Rinaldi MG. In vitro Amphotericin B resistance in clinical isolates of Aspergillus terreus, with a head-to-head comparison to voriconazole. J Clin Microbiol 1999; 37: 2343-2345.

8. Park KU, Lee HS, Kim CJ, Kim EC. Fungal discitis due to Aspergillus terreus in a patient with acute lymphoblastic leukemia. J Korean Med Sci 2000; 15:704-707.

9. Khamastha MA, Cuadrado MJ, Mujic F, Taub NA, Hunt BJ, Hughes GRV. The management of thrombosis in the antiphospholipid-antibody syndrome. N Eng J Med 1995; 332: 993-997.

10. Stevens DA, Kan VL, Judson MA et al. Practice guidelines for diseases caused by aspergillus. Clin Infect Dis 2000; 30:696-709.

11. Tritz DM, Woods GL. Fatal disseminated infection with Aspergillus terreus in immunocompromised hosts. Clin Infect Dis 1993; 16: 118122.

12. Masia Canuto M, Gutierrez Rodero F. Antifungal drug resistance to azoles and polyenes. Lancet Infect Dis 2002; 2: 550-563. 